\title{
Epochs and Evolution of Consciousness by Gebser and Barfield
}

\section{Sayyed Ali Mirenayat}

PhD Candidate in English Literature, Faculty of Modern Languages and Communication, Universiti Putra Malaysia

Elaheh Soofastaei

PhD Candidate in English Literature, Faculty of Modern Languages and Communication, Universiti Putra Malaysia

Hardev Kaur A/P Jujar Singh

Senior Lecturer in English Literature, Faculty of Modern Languages and Communication, Universiti Putra Malaysia *ali.mirenayat@yahoo.com, ela.soofastaei@yahoo.com, jshardev@yahoo.com

Doi:10.5901/mjss.2015.v6n5p450

\section{Abstract}

If all beings have consciousness in some way, so it is not something that is evolved by mankind. It has already and always existed. Evolution of consciousness refers to what human has now gained the power to select what he wants to become in the future based on developments in different areas, such as technology, medicine, and so on. Jean Gebser and Owen Barfield are two famous philosopher who have studied the evolution of consciousness from the pre-historic era to the modern age of information technology and cybernetics era. This paper precisely shed light on their examinations epochs of consciousness and its evolution.

Keywords: Consciousness, Evolution, Epoch, Idol, Participation, Figuration

\section{Introduction}

Consciousness is a thought-provoking phenomenon which originates from the operation of brain as the state of being conscious and responsive to environments. All forms of human evolution contain some sort of level of consciousness related to it, in order that in this way the different kinds of evolution can enhance. This has a particular characteristic that makes easy balance in the evolution progress. This is Darwinian evolution in which consciousness would have happened primarily in 200 million years back. This paper talks about the evolution epochs which have defined by Jean Gebser, and then Owen Barfield that has examined the evolution of consciousness in depth.

Jean Gebser (1905-1973), Swiss philosopher, theorizes that human consciousness is in transition in both mind and body. He remarks that the different epochs of consciousness are displayed by their connection to space and time. He speaks of the major structures of "epochs of consciousness". In the structures, we observe a chronological sequence in evolution of consciousness which starts since six million years ago and continues till the middle of twenty century. Examining this chain of evolution is one of the main goals that this paper follows.

Next, this paper will look at Owen Barfield (1898-1997) as a British philosopher and writer for about one century. He is known for his various descriptions of the evolution of consciousness. He defines the history of language as the entrance into understanding the history of consciousness which will be surveyed in this paper as a significant point.

\section{Epochs of Consciousness}

Consciousness consists of four epochs which are archaic, magic, mythic, and mental.

\subsection{Archaic (6 million years ago to 200 thousand years ago)}

Gebser describes it as a simple state of being in which there was no thought of changing nature and in which our imagination did not go away from meeting the instantaneous requires of the present. The archaic is called structure of "immersion" and also "uroboros" (or the serpent that eats its own tail) that indicates reptilian self-containment. It emerges 
from the "ever-present origin". There is no information about it. Algis Mickunas (1997) says,

The human being was totally immersed in the world unable to extricate himself or herself from that world. They were identical with that world.

\subsection{Magic (200 thousands years ago to 10 thousand years ago)}

This epoch succeeded the prior archaic epoch, and therefore, the archaic lost its efficiency and became deficient. Gods and goddesses appeared and were worshipped in ritual not only for the sake of using human will, but also for the sake of our own spiritual requirements.

"Primary process"(magical displacement and magical condensation together) have survived in language. Gebser says that, "in this magic structure, he makes the almost superhuman attempt to free himself from the jungle-like bonds and spell of his fusion with nature. Here lies the basis of all sorcery and magic, such as rainmaking, ritual, and countless other forms by which magic man tries to cope with nature" (1985, p51).

\subsection{Mythic (10 thousands years ago 1500B.C)}

This structure can be considered two-dimensional since it is characterized by fundamental polarities. It gives unity to consciousness. "The word is always a mirror of inner silence, and myth a reflector of soul. The blind or unreflective side of the mirror is necessary to produce the visible reflection" (Gebser, 67). In this structure, characters, objects, and events are intertwined together in fictions.

\subsection{Mental (1500B.C to the middle of $20^{\text {th }}$ century)}

The mental consciousness epoch reached its peak during the renaissance when perspective became concretized in painting. A non-pictographic form of writing in which an arbitrary letter that is not an image is bonded with an arbitrary sound is the alphabet. And also a set of letters arranged in a fixed order which is used for writing a language.

The invention of the alphabet (1500B.C to 1250B.C) initiated a new era in consciousness called "Mental" consciousness. Mental consciousness is a remarkable extrapolation of the alphabet. The fundamental features of the alphabet transferred as the main characteristic of mental consciousness.

In alphabet, there are three main features including abstraction, detachment, and linearity that I will explore them briefly in the following.

\subsubsection{Abstraction}

A "shift" beyond the magical image is abstract nature of the alphabet. Modern mental consciousness is abstract, because it engages with things independent of a grounded interiority. We can experience things abstracted from the foundation of interiority.

\subsubsection{Detachment}

In the alphabet, sound stops to be an event in time and becomes an object in space. The alphabet detaches sound from its main effectiveness of including consciousness in phenomena. In Detachment the alphabet makes us see sound. Sound is an event in time and it exists as it perishes. In Detachment magical and mythical mixing has decreased and in Linearity alphabetic writing involves sequence not at the same time. There is a distance in alphabetic literacy and in mental consciousness between the known object and the knowing subject. Distance is a disability of mental consciousness that demands to be healed.

\subsubsection{Linearity}

Alphabetized mental consciousness is linear. Mental consciousness is addition and horizontal.

The computer is as a form of the distance of mental consciousness. Mental consciousness is characterized by distance. We are here and things are there. Consciousness is entangled, magically intermingling with the animate world. Our consciousness is founded on distance. Distance emerged in human consciousness from the alphabet. The "evolution" of consciousness of the human kind is repeated in the "development" of consciousness of the human 
individual. Both "evolution" and "development" involve "differentiation" that means a moving away from the present form of consciousness.

\section{Owen Barfield and Evolution of Consciousness}

Owen Barfield in his book Saving the Appearances mentions that the autonomous object without interiority of mental consciousness is an "idol". He believes that idolatry is a synonym for mental consciousness and mental consciousness engages with idol. "The idols of the subtitle to Saving the Appearances are the "collective representations" - the phenomena of the physical world - as they are understood by modern science; that is, as completely unrelated to the imagination" (Lachman).

Owen Barfield also says,

... if appearances are correlative to human consciousness and if human consciousness evolves, then the future of the appearances, that is, of nature herself, must indeed depend on the direction which that evolution takes. (Saving the Appearances)

After Barfield published this book, various advancements warned to direct the evolution of consciousness in unwanted ways. His book is about art and imagining of God in which Barfield says, "Imagination is not simply synonymous with good." A methodology of mental consciousness that knows everything in reality as only "exteriors" in outside terms is "reductionism". "The world is relative to consciousness." Lewis Mumford (1895-1990) calls mental consciousness as a "disqualified universe" without "participation" that Owen Barfield calls. To Barfield, idolatry which is "a non-participating consciousness cannot avoid distinguishing abruptly between the concept of 'man,' or 'mankind,' or 'men in general' on the one hand and that of 'a man' - an individual human spirit - on the other." (Barfield, 183) He introduces an outline of the human consciousness history, including in new theory of human "participation" in nature. This participation includes a revolutionary understanding of the origin, difficult situation in the present time and the destiny of human being. There are three steps in it:

\subsection{Original participation ("inspiration")}

Participation is the extra-sensory relation between man and the phenomena. (Owen Barfield 40)

It is the reflected primordial state in mythical symbols of paradise when consciousness was expanded. Original participation was not mostly self-conscious, even though the experience of it would essentially be different from our present experience of perception. According to Barfield Original participation, is a "primal unity of mind and nature, with no separation between inner and outer worlds." He claims that nature is as subjective and as humans are. He believes nature was as subjective and inner and what we are. But slowly "unconscious nature" became focused on human consciousness. This procedure maintains gradually, with increasingly minor connection between our new "self" consciousness and its "unconscious" source, until we arrive at our present situation. At this time we are as far away from "original participation" (Lachman).The evolution of consciousness is correlative with the rise of conceptual reasoning and with the decline of original participation. He states that human should "leave the security of original participation in order for consciousness to take the next step in its evolution." (ibid) Barfield in his book mentions,

The essence of original participation is that there stands behind the phenomena, and on the other side of them from me, a represented which is of the same nature as me. Whether it is called "mana," or by the names of many gods and demons, or God the Father, or the spirit world, it is of the same nature as the perceiving self, inasmuch as it is not mechanical or accidental, but psychic and voluntary. (Saving the Appearances, p42)

\subsection{Modern participation}

It is distinguishing as much as it constructs an unbridgeable contravention between object and subject, man and cosmos. In here Barfield has no understanding of the figurative nature of phenomena because participation is kept out from awareness. There is a connection between Barfield's second step and participation in poetic remark and it involves the person's self-conscious effort to reconnect to nature and phenomena that their circumstances have extra-sensory and anyone should not be astonish to find that modern science growth in $17^{\text {th }}$ century would be the twin to this second step in the evolution of consciousness. 


\subsection{Final participation ("imagination")}

It is free from the evil of distance, abstraction and objectivity. It brought to fulfillment and embodied in Romantic Movement in literature in the early $19^{\text {th }}$ century that makes Coleridge between the others. In the end, although it may be signified in particular special individuals, final participation has not yet been attained. We can borrow from $19^{\text {th }}$ century biology the term ontogenetic and phylogenetic development, if we think of these three levels of participation and the three steps of evolution of consciousness as homologous. Therefore these three levels of participation in an individual (ontogenetic) could be said to recapitulate the three major steps in the evolution of human consciousness (phylogenetic).

Imagination is the supreme faculty in the mental consciousness. This similarity with C.T Coleridge's theory emphasizes the "difference in degree" of perception between primary and secondary imagination. Coleridge says: "imagination dissolves distance in order to recreation." There are endless ranges of consciousness. We can separate a "lower" end of the spectrum by imagining the entirely unreal and instinctual consciousness in animals. Owen Barfield says, "the world of final participation will one day sparkle in the light of the eye as it never yet sparkled early one morning in the original light of the sun" (161).

There are different stages of consciousness or awareness apart from the ownership of different facts. In fact, attainment of a definite stage of consciousness is essential before we can own any facts at all - as opposed to their owning us in a dream. There are ways of knowing besides the knowing of facts. While the knowledge of the ancients was definitely not a technological or scientific savvy, we cannot for that reason alone dismiss it. Objectivity brings up by distance. Mental consciousness reveals a duty to know everything objectively to see it as autonomous. There is a relation between final and original participation when human accept that "in the course of the earth's history, something like a Divine Word has been gradually clothing itself with the humanity it first gradually created - so that what was first spoken by God may eventually be re-spoken by man" (Saving the Appearances, 67).

\section{The Modern World and Consciousness}

Barfield uses the word of figuration. Every structure of consciousness offers a certain style of figuration. We know the world only a figuration. Consciousness configures the world in a certain style. The world that you see and know and experience owes you the consciousness that you bear. Figuration is the process by which mere sensations are constructed by the percipient mind into recognizable objects. The world is relative to consciousness. We never can tell what the world would be. We are living in different worlds together. History is a tableau of changing world. For sure, there is no transformation between the consciousness of the ancient Egypt and the consciousness of our modern world. When we see the sky, we all see the same sky. To Barfield, this view is completely false. He believes that the ideas in different ages differ, and people in the past saw the sky different than us at the present time. He claims that not only views, but also consciousness changes over time. One of his interesting conclusions is about all views about the too distant past,

They project a picture of that world as it would be seen by a consciousness alive today. We have no way of knowing what that world looked like to a different consciousness because we have no record from a consciousness of that time. We can only speculate...it's nevertheless our consciousness that discovers fossils and organizes them into the schemata of ancient life. (Lachman)

Passage to India by Walt Whitman is a definitive poem of consciousness and technology. Technology always mimics. The world is highly cargo of magical and mythical adherence of participation in mental consciousness. Marshal McLuhan says that any type of communication technology is an extension such as Radio, TV, Phone and etc. Cybertechnology in extension is as an extension of consciousness such as the Internet and an amplification of consciousness. That is natural tendency to see internet as an "extension" of consciousness. Technology is as post-mental consciousness. In the modern epoch, there is a tendency between men and women. Marshall McLuhan knows "technology as an extension of the human body. An extension occurs when an individual or society makes or uses something in a way that extends the range of the human body and mind in a way that is new... a microscope or telescope is a way of seeing that is an extension of the eye. He also considers that next to each extension, technology is bringing some sort of amputation. The art of adopting technology is to maximize the extension effect while minimizing the imputation it brings" (Bruck, p130). The extension of a technology like the automobile "amputates" the need for a highly developed walking culture, which in turn causes cities and countries to develop in different ways. McLuhan believed that mankind has always been fascinated and obsessed with these extensions. Technology is an extension of our own natural faculties.

There is wizardly in the conquest of time such as Xanadu by Coleridge. It is the gathering of all human knowledge in one space in one time. The internet is Xanadu in the palm of your hand. And this Xanadu is a miracle of technology. 
The computer is "an empty abstraction", is "pure unblinking wakefulness constructed to nullity." "The word spirit has many connotations. It can mean an animating or vital principle that gives life to physical entities. Spirit can also imply a special frame of mind, a soul, a ghost or a collective attitude such as school spirit." (Hagerty, 2000) Cyberspace or the Internet is a place of spirit or a spiritual place. But it does not mean that cyberspace is all the time respectful, but it is a reflection of who we really are in the Information Age.

The Internet wants to have a main effect on your life. Some of us mistakenly think we can stay away from becoming entangled in its World Wide Web. During an age of unparalleled growth in human or machine symbiosis, the Internet is actually the physical appearance of the enduring evolution of human consciousness. "The Internet has become the central nervous system of our planet's social and economic life and is the physical manifestation of a place called cyberspace." (ibid) In primitive times it was the fire that used as the technology for gathering us together. But at the end of the 20th century we had developed a whole world of technologies to help us stay connected to each other.

\section{Conclusion}

From pre-history era to the ancient Egypt and to the present time, consciousness has evolved to complete. Living in the Stone Age is replaced by the Information Age (Cyberspace). Jean Gebser has found four epochs of consciousness, including archaic, magical, mythical, and mental. He believes that human has been evolving from the beginning. In each epoch, consciousness comes forward and evolves step by step. After, Owen Barfield defines the history of language as the entry into understanding the history of consciousness. By introducing of an outline for the human consciousness, such as human "participation" in nature, it includes a revolutionary understanding of the origin which contains three steps, including original participation, modern participation, and final participation. He uses the word of figuration in which every structure of consciousness offers a definite style of figuration. There is a balance in figuration between what is given to human from nothing and what human contributes from within. It continues to the modern era in which something like the Internet is, in fact, the physical appearance of consciousness evolution.

\section{References}

Barfield, Owen.(1988). Saving the Appearances: A Study in Idolatry. Wesleyan University Press. Bruck, Peeter A. (2008). Multimedia and E-content Trends: Implications for Academia. Viewing + Teubner, Heidelberg, p.130. Gebser, Jean.(1985). The Ever-Present Origin. Ohio University Press, pp.51-67. Hagerty, Lawrence. (2000). The Spirit of the Internet: Speculations on the Evolution of Global Consciousness.

Lachman, Gary. Owen Barfield and the Evolution of Consciousness. Retrieved from http/l:www.davidlavery.net/barfield/barfield scholarship/lachman.html

Mickunas, Algis.(1997). An Introduction to the Philosophy of Jean Gebser. Integrative Investigations. Volume 4 Number 1. Pages 8-21. 